\title{
FRONTINO MEDIEVAL, UNA VEZ MÁS
}

\author{
Ángel Gómez Moreno
}

En noviembre de 1986 se celebraron en la Casa de Velázquez de Madrid unas jornadas de investigación sobre la Leyenda en las que participaron diversos estudiosos de España y Francia. El resultado final de tal encuentro lo constituye el libro La Légende. Anthropologie, Histoire, Littérature, Madrid: Casa de Velázquez - Universidad Complutense, 1989, en el que se incluye mi participación "Leyenda y hagiografía: el caso de San Vitores" (págs. 173-191). En dicho trabajo intento demostrar hasta qué punto fue común la contaminación entre distintas leyendas hagiográficas, que, a menudo, aceptaron también materiales heroicos o literarios de índole diversa.

La vida de este santo burgalés es realmente económica en lo que respecta a los elementos constituyentes de la primera versión de que tenemos noticia : el Pasionario de Silos, del siglo xI, que se conserva en la Biblioteca Nacional de París (cod. lat. 2179); en ella se nos cuenta cómo San Vitores fue martirizado por los judíos en el siglo Ix, con un motivo central: la crucifixión del santo y la amonestación al verdugo para que el clavo pueda entrar en sus pies $^{1}$. Un códice de la primera mitad del siglo xv (ms. 9.481 de la Biblioteca Nacional de Madrid) incorpora ya todos los elementos legendarios con que se conoce la vida del santo en la actualidad, los mismos que recoge más tarde Andrés Gutiérrez de Cerezo, célebre discípulo de Nebrija que llevó a la imprenta la vida del patrono de su pueblo ${ }^{2}$; entre éstos, los dos detalles prin-

\footnotetext{
1 Editado en el Catalogus Codicum hagiographicorum Latinorum Bibliothecae $\mathrm{Na}$ tionalis Parisiensis (Bruselas, 1893), vol. III, págs. 504-506.

2 Las dos versiones tardomedievales conocidas pueden leerse ahora en mi artículo, donde se enmiendan los múltiples errores de Tomás de Izarra al estudiar el códice madrileño, "En torno al pergamino relativo a San Vitores existente en la Biblioteca $\mathrm{Na-}$ cional de Madrid", Boletín de la Comisión Provincial de Monumentos de Burgos, 6 (1945), 593-602. La versión de Andrés Gutiérrez de Cerezo es básicamente la misma que la anterior, pero su difusión fue mucho mayor gracias a que se imprimió hacia 1487
} 
cipales son el carácter de santo cefalóforo de San Vitores (tras su decapitación, claro está) y su astucia, puesta de relieve al liberar la villa de Cerezo del cerco a que la sometia Almanzor. Asi narra este último hecho el códice custodiado en la Biblioteca Nacional:

La madre e otros muchos de la çibdat llegaron alli do el santo estaua, e desque vieron que tenía la cabeça cortada començaron todos de fazer muy grant llanto, deziendo así : “ $¡ \mathrm{O}$, Señor, cómmo somos perdidos todos los xpistianos! ¿Agora quién nos consejará o quién nos defenderá agora de aquestos malos enemigos?” Et dixeron al santo mártyr: “O, bienaventurado, rrogámoste por Ihesu, solo Dios, que ansí commo as seydo nuestro abogado en la vida que ansi lo quieras ser para siempre ante el Nuestro Señor Dios por nos e por toda esta çibdat".

Et allí ge lo otorgó el santo mártyr, e díxoles a todos: “Amigos e hermanos, estad firmes en la fe de Nuestro Señor Ihesu Xpisto, e de ese poco pan que tenedes, que es vna emina de trigo, fartad una vaca e fazelda salediza de vuestra çibdat, e desque la vieren los moros echarle han los canes e matarla han, e ansí seredes deçercados." Estonçes en Çerezo non auía más de aquella emina de trigo e la fe era ya poca en los xpistianos, saluante por el santo mártyr que los confortaua con las sus buenas palabras. Et dixéronle: "Padre, sabé qué en toda esta nuestra çibdat non podriamos auer nin fallar tan solamente vn çelemín de trigo nin sabemos dónde lo fallaremos." E díxoles el santo mártyr: "Ydvos açerca de la Iglesia de la Llana, e ay biue vna buena muger que tiene vna emina de trigo en vn orzo e tiénelo so tierra debaxo de la su cama; e tomarlo hedes e fartat vna vaca segunt que dicho he e luego seredes deçercados." Et fuéronse para allá e fallaron el trigo segunt que les auía dicho; e tomaron aquel poco trigo e fartaron dello aquella vaca, e feziéronla salediza. El rrey e los moros, desque la vieron asi salyr, echáronle los canes e matáronla a lançadas, e el rrey e los moros, desque vieron que la vaca estaua farta de trigo, dixeron: "Ha tantos años que estamos sobre esta çibdat e avn fartan los ganados de trigo: vianda tienen para muchos años." Et alçaron de alli sus tiendas et fuéronse por el puerto de La Morcuera. Et así fueron deçercados.

No muy lejos anda Andrés Gutiérrez de Cerezo, cuyo texto se expresa del modo siguiente:

En esta misma ora el mártyr començó a llamar todos los moradores de la villa, a los quales, ansi consolando como amonestando porque mucho començauan a desfallesçer de la fe cathólica, en esta manera siguiente dixo: "Gozaos ermanos míos porque ya es llegado el tiempo en el qual seréis librados del çerco, para rremedio de lo qual, conuiene luego hagáys lo que ahora diré :

en Burgos, en la imprenta de Fadrique de Basilea; tras perderse la pista del único ejemplar conservado, las noticias de que disponemos parten de un viejo microfilm conservado en la Biblioteca Nacional de Madrid (R-100.181), con facsimil editado en Burgos: Junta de Castilla y León, 1985. Con todo, la leyenda se salvó para la posteridad en la Flos sanctorum de Carrasco, publicada en 1567 en Alcalá de Henares. 
ydvos para Sancta María de la Llanna y entrad en casa de vna vieja - el nombre de la qual yo çelebrado non le hallo- y como entráredes preguntadle su cama quál es, porque deuaxo della hallarés vna hemina de trigo - ca en toda la villa otra hallar non se podía- y hartad vno vaca, la qual hazedla que salga por las puertas de la villa haza los rreales de los moros, y como los moros la vieren luego echarán las lanças en ella y como vieren que el trigo sale pensarán vna de dos cosas: o que vos queda mantenimiento para más largo tiempo o que agora de nuebo vos an traydo prouisión de otra parte." Lo qual todo ansí cumplieron como el mártyr auia mandado se hiziesse. Y como los moros viessen que después de siete años los que estauan dentro en el çerco hartauan la vaca de trigo creyeron que en ninguna manera podrian tomar por falta de prouisión la villa, segund que hasta allí tenían esperado porque combatir non se podia, ca era tan fuerte y en alto puesta que era marauilla. Pues que ansí es, los moros mucho desconfiando començaron a mouer sus rreales que enderredor de la villa estauan e yrse haza el puerto llamado Morcuera. E ansí, en conclusión, por industria y rruegos del glorioso mártyr Sant Victores, los vezinos de la villa de Çereso fueron librados de la persecuçión de los moros y del cerco en que estauan.

Como se puede comprobar, uno y otro texto son idénticos en su contenido, aunque Gutiérrez de Cerezo intenta ser mucho más claro en su presentación de la vida de San Vitores (por ello, hace que el santo adelante el resultado de su ardid y elimine la sorpresa propia de este tipo de relatos). En mi artículo señalé la presencia de este motivo en diversos textos medievales, entre los cuales destaca la obra de Walter Burley De vita et moribus philosophorum, que tuvo una notable difusión por toda Europa desde comienzos del siglo xiv ${ }^{3}$. El libro de Burley inserta la anécdota en su biografía del sabio Bías de Prienne, que liberó esta ciudad del acoso de sus enemigos (sigo, con algún pequeño cambio, la edición de Knust, pág. 34) :

En otro tiempo, segunt cuenta ese mesmo Laercio, como uno que se llamava Aliato toviese sitiada la cibdat de Yprimén y esperase que los yprimenses avían de fallescer por fanbre, Biante con tal arte encubrió el defecto que los de la cibdad padescían: fizo engordar dos mulas y lançarlas fuera de la cibdad en lugar que fortuitamente fuesen tomadas de los enemigos, las quales como las viese Aliato entendió que los de la cibdad estavan muy abondados de vituallas, y enbió a Biante que saliese a él a tratar de concordia.

3 Conozco tres copias de la versión castellana medieval: una escurialense (ms. h.III.1), utilizada por H. Knust en su edición, Gualteri Burlaei liher De vita et moribus philosophorum, Tubinga, 1886; otra más en la Real Academia de la Historia (ms. San Román 125) rescatada por mí, "Manuscritos medievales de la colección San Román (RAH)", Varia Bibliographica. Homenaje a José Simón Díaz (Kassel, Edition Reichenberger, 1987), págs. 321-328; por fin, otro códice, también desconocido hasta ahora, se encuentra en la Biblioteca de Palacio, como se podrá comprobar en breve en el catálogo de manuscritos medievales de ese centro preparado por Charles B. Faulhaber y por mí. Se impone una nueva edición de esta obra. 
Como ya demostró Kerkhof, del texto de Burley parte, sin duda, el proemio del Marqués de Santillana al Conde de Alba que introduce el Bias contra Fortuna ${ }^{4}$. Sin embargo, otras documentaciones arrancan directamente de la obra que, a mi modo de ver, sirve de fuente al De vita et moribus philosophorum, que no es otra que el Strategematon de Frontino (siglo I d. C.), en su capitulo XVI ("Quemadmodum efficiatur ut abundare videantur quae deerunt"):

Thraces in arduo monte obsessi, in quem hostibus accessus non erat, conlato viritim exiguo tritico paucas oves paverunt et egerunt in hostium praesidia: quibus exceptis et occisis, cum frumenti vestigia in visceribus earum apparuissent, opinatus hostis magnam vim tritici superesse eis, qui inde etiam pecora pascerent, recessit ab obsidione. (Ed. Loeb. Classical Library, Frontinus, Stratagems and Aqueducts [Cambridge-Londres, Harvard University Press \& William Heinemann, 1950], pág. 252.)

A la vista de este testimonio, cabe afirmar que la leyenda tardomedieval de San Vitores tiene, como ocurre con Burley, su fuente directa en Frontino, que, paulatinamente, se nos revela como uno de los autores latinos más leídos en la Edad Media ${ }^{5}$. A su vez, la anécdota narrada por este tratadista guarda un notable parecido con otra incluida en el célebre compendio de Valerio Máximo De dictis factisque memorabilibus libri novem, en el capitulo dedicado a las estratagemas de los romanos (VII, 4,3$)^{8}$. Más que de influjo de

4 En su edición del Bias, Madrid, Aguirre (Anejo XXXIX del BRAE, 1983), que añade el texto de Burley como apéndice en págs. 247-248.

5 No creo preciso repetir algunos de los ricos materiales amasados por Lola Badía en "Frontí i Vegeci, mestres de cavalleria en català als segles xıv i xv", Boletín de la Real Academia de Buenas Letras de Barcelona, 39 (1983-1984), 191-215, o mis propias noticias en "Una forma especial del tópico de modestia", La Corónica, 12 (1983), 71-83. Junto a códices que conservan versiones en distintas lenguas vernáculas, catalanas y castellanas incluidas, disponemos en este momento de abundante información sobre la buena estrella de Frontino en el Medievo: su lectura es recomendada por varios cánones de autoridades y hasta por el mismo Dante en su De vulgari eloquentia o por Juan de Salisbury en el Policraticus; su presencia se intuye incluso donde menos cabría esperarla: en uno de los pasajes del Poema de mio Cid (Colin Smith, "Fuentes clásicas de dos episodios del Poema de Mio Cid”, Estudios cidianos [Madrid, Cupsa, 1977], págs. 107-123.

- A pesar de las evidentes diferencias, el espíritu del relato es el mismo en Valerio Máximo: "Illud quoque maioribus et consilio prudenter et exitu feliciter prouisum; cum enim urbe capta Galli Capitolium obsiderent solamque potiendi eius spem in fame eorum repositam animaduerterent, perquam callido genere consilii Romani usi unico perseuerantiae inritamento uictores spoliauerunt: panes enim iacere conpluribus e locis coeperunt. quo spectaculo obstupefactos infinitamque frumenti abundantiam nostris superesse credentes ad pactionem omittendae obsidionis conpulerunt, misertus est tunc profecto Iuppiter Romanae uirtutis, praesidium ab astutia mutuantis, cum summa alimen- 
un autor sobre otro, hemos de hablar de un motivo común que pudo transmitirse tanto en forma escrita (tal vez estaba presente en otros grandes anecdotarios, como en la versión extensa de Tito Livio, hoy desconocida, a la que tantas veces acudió Valerio Máximo) como en forma oral (en sus diversas variedades, muestra un buen talante folclórico). Sea como fuere, esta nueva huella de Frontino en la cultura medieval peninsular invita a proseguir con investigaciones adicionales que, sin ningún género de duda, depararán no pocas sorpresas ?

\footnotetext{
torum inopia proici praesidia inopiae cerneret. igitur ut uafro, ita periculoso consilio salutarem exitum dedit" (ed. de Kempf [Stuttgart, Teubner, 1966], págs. 346-347).

7 Esta batida habría que llevarla a cabo en distintos grupos textuales de contenido bélico: $a$ ) obras de ficción caballeresca : romans; $b$ ) documentos: crónicas, cartas de batalla, carteles de desafío y actas de pasos de armas, y c) libros teóricos de diverso contenido: estrategia militar, retos y desafíos, armas para el combate, escudos y blasones, derecho en la guerra, etc. Como punto de partida, puede considerarse un temprano trabajo propio, "La caballería como tema en la literatura medieval española: tratados teóricos", Homenaje a Pedro Sains Rodríguez (Madrid, F. U. E., 1986), págs. 311-323; advierto de antemano sobre sus numerosas erratas, como un divertido Bólugas (por Bohigas) en la última nota, y sobre un claro desliz (también ajeno, por olvido de una nota): el anónimo Libro de la guerra (ms. $6.526 \mathrm{BNM}$ ), como he señalado en otro lugar, es fundamentalmente un Vegecio (fue editado por Lucas de Torre en Revue Hispanique, 38 (1914), 497-531, quien se lo atribuyó a don Enrique de Villena).
} 